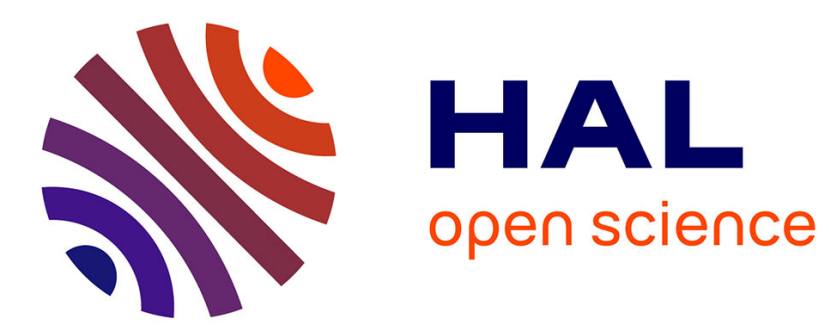

\title{
Characterization of helium bubble size and faceting by electron holography
}

\author{
Etienne Snoeck, Jérôme Majimel, M. O. Ruault, Martin Hÿtch
}

\section{To cite this version:}

Etienne Snoeck, Jérôme Majimel, M. O. Ruault, Martin Hÿtch. Characterization of helium bubble size and faceting by electron holography. Journal of Applied Physics, 2006, 100 (2), 023519 (5 p.). 10.1063/1.2216791. hal-00090302

\section{HAL Id: hal-00090302 https://hal.science/hal-00090302}

Submitted on 7 Mar 2018

HAL is a multi-disciplinary open access archive for the deposit and dissemination of scientific research documents, whether they are published or not. The documents may come from teaching and research institutions in France or abroad, or from public or private research centers.
L'archive ouverte pluridisciplinaire HAL, est destinée au dépôt et à la diffusion de documents scientifiques de niveau recherche, publiés ou non, émanant des établissements d'enseignement et de recherche français ou étrangers, des laboratoires publics ou privés. 


\section{Characterization of helium bubble size and faceting by electron holography}

E. Snoeck, J. Majimel, M. O. Ruault, and M. J. Hÿtch

Citation: Journal of Applied Physics 100, 023519 (2006); doi: 10.1063/1.2216791

View online: https://doi.org/10.1063/1.2216791

View Table of Contents: http://aip.scitation.org/toc/jap/100/2

Published by the American Institute of Physics

\section{Articles you may be interested in}

In situ controlled modification of the helium density in single helium-filled nanobubbles

Journal of Applied Physics 115, 123508 (2014); 10.1063/1.4869213

Fusion materials science: Overview of challenges and recent progress

Physics of Plasmas 12, 058101 (2005); 10.1063/1.1880013

Influence of interfaces on the storage of ion-implanted He in multilayered metallic composites

Journal of Applied Physics 98, 123516 (2005); 10.1063/1.2149168

Evolution of point defect clusters in pure iron under low-energy $\mathrm{He}^{+}$irradiation

Journal of Applied Physics 89, 4752 (2001); 10.1063/1.1357785

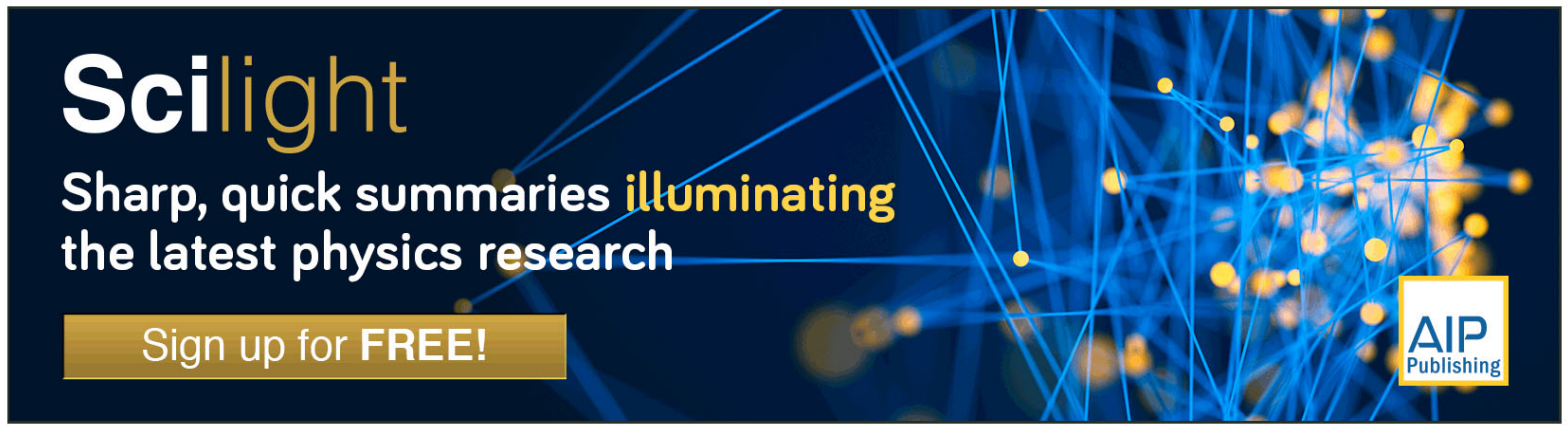




\title{
Characterization of helium bubble size and faceting by electron holography
}

\author{
E. Snoeck ${ }^{\text {a) }}$ \\ Centre d'Elaboration de Matériaux et d'Etudes Structurales, 29 rue Jeanne Marvig, \\ F-31055 Toulouse Cedex 4, France \\ J. Majimel \\ Institut de Chimie de la Matière Condensée de Bordeaux - Université Bordeaux 1, \\ 87 Avenue du docteur Schweitzer, F-33608 Pessac Cedex, France \\ and Centre d'Etudes de Chimie Métallurgique, 15 rue Georges Urbain, F-94407 Vitry/Seine, France
}

M. O. Ruault

Centre de Spectrométrie Nucléaire et de Spectrométrie de Masse, Université de Paris-Sud, Batiment 108, F-91405 Orsay Cedex, France

\author{
M. J. Hÿtch \\ Centre d'Elaboration de Matériaux et d'Etudes Structurales, 29 rue Jeanne Marvig, \\ F-31055 Toulouse Cedex 4, France and Centre d'Etudes de Chimie Métallurgique, 15 rue Georges Urbain, \\ F-94407 Vitry/Seine, France
}

(Received 1 December 2005; accepted 17 May 2006; published online 24 July 2006)

\begin{abstract}
Iron-9\% chromium alloy of controlled purity and microstructure was helium implanted and studied using transmission electron microscopy and electron holography (EH). Fresnel imaging is compared with electron holography for a set of identical helium bubbles of size 2-4 $\mathrm{nm}$. Electron holography reveals that the bubbles are, in fact, faceted and the lateral and projected dimensions of the cavities are measured. Current measurements allow the detection of $1 \mathrm{~nm}$ diameter bubbles using EH. The merits of conventional and holographic techniques are discussed and future improvements anticipated. Electron holography seems to be the ideal technique for investigating the morphology of helium bubbles and cavities in general. (c) 2006 American Institute of Physics.
\end{abstract}

[DOI: 10.1063/1.2216791]

\section{INTRODUCTION}

Helium gas is now widely acknowledged to be a major cause of irradiation embrittlement in metals and alloys. ${ }^{1}$ The most widely accepted model of helium induced embrittlement is based on the stress-induced growth of cavities nucleated from helium bubbles. Cavities which grow and coalesce on grain boundaries form cracks in irradiated alloys. ${ }^{2}$ More recently, it has been found that the brittle intergranular fracture results in addition from a hardening due to a high density of subnanometric helium bubbles, detected principally by small angle neutron scattering (SANS). ${ }^{3}$ However, despite abundant work on the helium embrittlement phenomenon, detailed characterization of intrinsic properties of helium bubbles is still lacking.

Iron-chromium alloys (from $7 \%$ to $12 \% \mathrm{Cr}$ ) are proposed as structural materials for the spallation target of the accelerator driven system (ADS) for nuclear waste transmutation. ${ }^{4}$ Spallation elements such as helium or hydrogen are generated by nuclear reactions. For example, helium is produced primarily by an $(n, \alpha)$ reaction: a reaction between a neutron and the nucleus of a lattice atom to form the nucleus of a new atom and an $\alpha$ particle (a helium ion). Iron-9\%chromium alloy of controlled purity has been prepared at the CECM-CNRS and implanted with low energy helium ions in order to characterize the helium bubble microstructures. ${ }^{2}$ Controlling the purity is particularly impor-

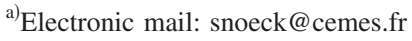

tant to separate the different parameters involved in defect nucleation due to external factors such as helium implantation and point defects induced by irradiation. Moreover, experimental observations are facilitated in precipitate-free material.

Several studies of helium bubbles in pure-iron, ironchromium ferritic alloys, or silicon carbides have already been published. ${ }^{3,5-7}$ Implanted helium interstitial atoms form large faceted bubbles or two-dimensional helium platelets staying between two lattice planes of the matrix. Such faceted microstructures minimize the interface energies in a more efficient way than round-shaped bubbles. Faceted bubbles and plateletlike structures are likely to drastically modify the mechanical properties of the alloy. A precise determination of the morphologies of all the helium bubbles of different sizes is therefore needed to link their intrinsic properties to their internal pressure.

Internal pressure can be measured by electron energy loss spectroscopy ${ }^{8}$ whereas the standard method used until now to observe and characterize the morphology of helium bubbles is Fresnel microscopy. ${ }^{9}$ However, this conventional transmission electron microscopy (TEM) technique suffers from numerous disadvantages: notably a nondirect relation between images and bubble size and shape due to the highly out-of-focus imaging conditions required. In addition, small bubbles $(<5 \mathrm{~nm}$ diameter) have limited contrast. Under such conditions, extensive image simulations are necessary to determine bubble size, and precise shape determination is generally excluded. For this reason, we propose in this paper to 
TABLE I. Main metalloidic impurities content in $\mathrm{Fe}-9 \% \mathrm{Cr}$ alloy determined by GDMS

\begin{tabular}{ccccccccccccc}
\hline \hline Element & $\mathrm{C}$ & $\mathrm{B}$ & $\mathrm{O}$ & $\mathrm{N}$ & $\mathrm{S}$ & $\mathrm{P}$ & $\mathrm{Ni}$ & $\mathrm{Cu}$ & $\mathrm{Al}$ & $\mathrm{Ti}$ & $\mathrm{Si}$ & $\mathrm{Zn}$ \\
\hline wt. ppm & 8 & 3 & 2 & $<1$ & 0.82 & 0.04 & 0.80 & 0.50 & 0.23 & 0.20 & 0.15 & 0.08 \\
\hline \hline
\end{tabular}

use electron holography as an accurate way of determining bubble sizes and shapes even for the smallest bubbles. Both techniques will be employed on identical specimen areas to allow a fair comparison. Electron holography has previously been used for the study of faceted nanoparticles ${ }^{10}$ and faceted voids in silicon of the much larger size of $20 \mathrm{~nm} .{ }^{11}$

\section{EXPERIMENT}

\section{A. Material and helium implantation}

High purity $\mathrm{Fe}-9 \%$ wtCr alloy is prepared at the CECM by levitation melting in helium atmosphere controlled by gas-phase chromatography. The initial iron ingot is prepared from 99.998\% Johnson-Matthey Putratonics powder by zone melting and heat treatment: a bar is formed by compaction of the powder and melting in helium atmosphere. This bar undergoes five passes of horizontal zone melting in helium and is zone refined five times in purified dry hydrogen. ${ }^{12}$ The initial electrolytic chromium undergoes four passes of horizontal zone melting in hydrogen and is then annealed at $1300{ }^{\circ} \mathrm{C}$ during $20 \mathrm{~h}$ in hydrogen. ${ }^{13}$ Iron and chromium are finally melted in helium at $1600{ }^{\circ} \mathrm{C}$. Iron-chromium ingots $(\oslash 13 \mathrm{~mm})$ are first cold rolled down to $0.6 \mathrm{~mm}$ thick, then annealed $2 \mathrm{~h}$ under hydrogen atmosphere, and air cooled. The sheets are once again cold rolled down to $0.13 \mathrm{~mm}$ thick, annealed $1 \mathrm{~h}$ under hydrogen atmosphere at $980{ }^{\circ} \mathrm{C}$, and air cooled. These treatments are finally followed by a final $2 \mathrm{~h}$ annealing at $700{ }^{\circ} \mathrm{C}$ and air cooling.

The main metalloidic impurities are determined by global discharge mass spectrometry (GDMS) and reported in Table I.

$\mathrm{Fe}-9 \% \mathrm{Cr}$ samples are prepared by punching out $3 \mathrm{~mm}$ diameter disks, mechanical thinning to $0.6 \mu \mathrm{m}$, and electropolishing in a Tenupol 5 (Stuers) using a solution of acetic acid and perchloric acid (0.95:0.05) at $15{ }^{\circ} \mathrm{C}$ and $50 \mathrm{~V}$. The specimens are finally mounted in a TEM specimen holder designed for high temperature annealing and implanted with $8 \mathrm{keV} \mathrm{He}$ ions at $400{ }^{\circ} \mathrm{C}\left(T / T_{m} \approx 0.25\right)$, using the CSNSM low energy ion accelerator in line with a TEM. The implanted helium contents were chosen to range from 6.5 $\times 10^{3}$ to $11 \times 10^{4}$ at. ppm (atomic parts per million) corresponding to $0.3-4.5 \mathrm{dpa}$ (displacements per atom). Furthermore, according to these implantation conditions and using the SRIM code, ${ }^{14}$ the maximum helium ion concentration is found to be in the projected depth range of 10-90 nm below the surface.

\section{B. Transmission electron microscopy}

Conventional TEM observations were carried out using a JEOL 2000EX operating at $200 \mathrm{kV}$ whereas a Philips CM12 operating at $120 \mathrm{kV}$ is used in line with the ion implanter to perform the in situ TEM observations during the implantation.

For the visualization of helium bubbles, special out-offocus conditions are used. ${ }^{9}$ The specimen is oriented far from any Bragg conditions and large through focus series, in a large range of $+/-$ a few microns, is taken so that Fresnel fringe appear around the bubbles. The fringe contrast is reversed when passing from negative defocus (underfocus of the objective lens) to positive (overfocus) while no significant contrast is observed close to the exact focus position. The size of the bubbles is determined studying the location of Fresnel fringes for different values of defocus. Extra experimental problems are introduced due to the fact that $\mathrm{FeCr}$ is ferromagnetic and the astigmatism and beam alignment need to be continually corrected.

\section{Electron holography}

Off-axis electron holography is based on the interference between a reference electron wave that has passed through vacuum and one that has been phase shifted due to its interaction with an object. The analysis of the resulting interference pattern (hologram) allows the local phase shift of the electron beam to be recovered. In a nonmagnetic sample, the phase shift $\phi$ of the electron wave is proportional to the local changes electrostatic potential projected along the electron pass $^{15,16}$ and is given by the expression

$$
\phi(x, y)=C_{E} \int V_{o}(x, y, z) d z
$$

where $x, y$ lie in the plane of the sample, $z$ is the incident electron beam direction, $C_{E}$ is a wavelength-dependent constant $\left(C_{E}=7.29 \times 10^{6} \mathrm{rad} \mathrm{V}^{-1} \mathrm{~m}^{-1}\right.$ at $\left.200 \mathrm{kV}\right)$, and $V_{o}$ is the mean electrostatic potential. For the bubbles of interest here, the electrostatic contribution to the phase shift is associated solely with the mean inner potential (MIP), i.e., the local composition and thickness of the sample. ${ }^{17}$ Assuming uniform composition the phase becomes

$$
\phi(x, y)=C_{E} V_{o} t(x, y),
$$

where $V_{o}$ is the mean inner potential for the matrix $[\sim 21 \mathrm{~V}$ for $\mathrm{FeCr}$ (Ref. 18)] and $t(x, y)$ the thickness of the specimen. In our ion implanted iron-chromium alloy, the lack of material associated with the presence of the He bubbles will reduce projected specimen thickness locally. The associated phase shift can then be imaged by electron holography with a very high spatial resolution.

Off-axis electron holography experiments were carried out on the SACTEM-Toulouse, a Tecnai F20 (FEI) FEG $200 \mathrm{kV}$ TEM specially equipped with a spherical aberration corrector (CEOS). Holograms were recorded on a 1024 $\times 1024$ SlowScan Gatan camera with a biprism polarization of $120 \mathrm{~V}$ and exposure times of about $4 \mathrm{~s}$. Within these conditions the interference fringes periodicity is $0.19 \mathrm{~nm}$ and a fringe contrast of between $15 \%$ and $25 \%$. Any additional phase shifts of the beam due to the effect of the microscope optic elements are removed acquiring a reference hologram and subtracting it following the method described, for instance, in Ref. 19. The mask used in Fourier space for the 

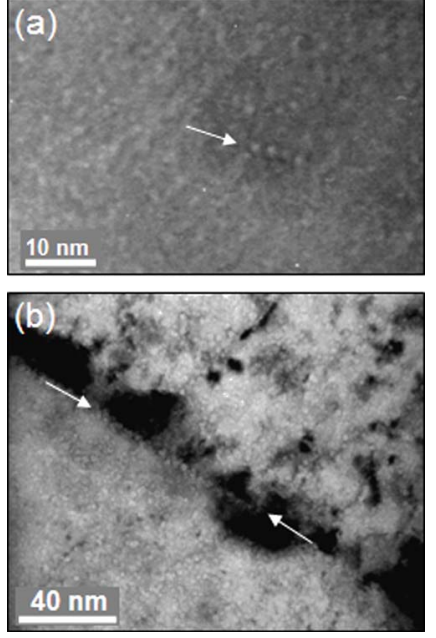

FIG. 1. TEM bright field micrographs of helium bubble microstructures in $\mathrm{Fe}-9 \% \mathrm{Cr}$ alloy after $8 \mathrm{keV} \mathrm{He}^{+}$implantation at $400{ }^{\circ} \mathrm{C}$. Helium bubbles preferentially first nucleate on dislocations [marked by arrow in (a) extracted from in situ experiments] and on grain boundaries [marked by arrows on (b)]. For the highest helium content, bubbles fill all the grain.

phase reconstruction had a radius of $1.6 \mathrm{~nm}^{-1}$, thus producing a lateral resolution of $0.6 \mathrm{~nm}$ in the phase images.

\section{HELIUM BUBBLE MICROSTRUCTURES}

\section{A. Bubble nucleation and growth mechanisms}

Helium bubbles preferentially nucleate on grain boundaries and on dislocations appearing during the elaboration phase as reported in Figs. 1(a) and 1(b). Finally, as the dose increases, bubbles will fill the whole grain. The variation in bubble size with helium dose is published elsewhere ${ }^{2}$ for an $\mathrm{Fe}-9 \% \mathrm{Cr}$ alloy of controlled purity. It has been shown, using Fresnel contrast, that for low-to-medium helium content, bubbles grow continuously with increasing helium dose and appear round shaped.

Beyond a threshold value of about $7.5 \times 10^{4}$ at. ppm $\mathrm{He}^{+}$, the size distribution spreads and small round-shaped bubbles coexist with larger faceted ones (see Fig. 2). From this stage, the number of point defects formed in the vicinity of the helium bubbles modifies significantly the inner potential of the $\mathrm{Fe}-\mathrm{Cr}$ matrix and allows the migration of $\mathrm{He}$ atoms from the small bubbles. By trapping these released atoms before they can diffuse to the surface, the largest helium bubbles will grow according to a classical Ostwald ripening process, forming facets with a more efficient relaxation field around them.

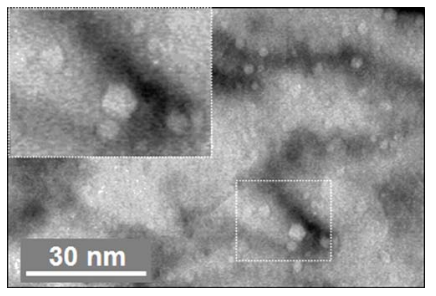

FIG. 2. TEM bright field micrograph of helium bubble microstructure in $\mathrm{Fe}-9 \% \mathrm{Cr}$ alloy after $8 \mathrm{keV} \mathrm{He}{ }^{+}$implantation at $400{ }^{\circ} \mathrm{C}$. Different spherical and faceted bubble morphologies are presented inset.
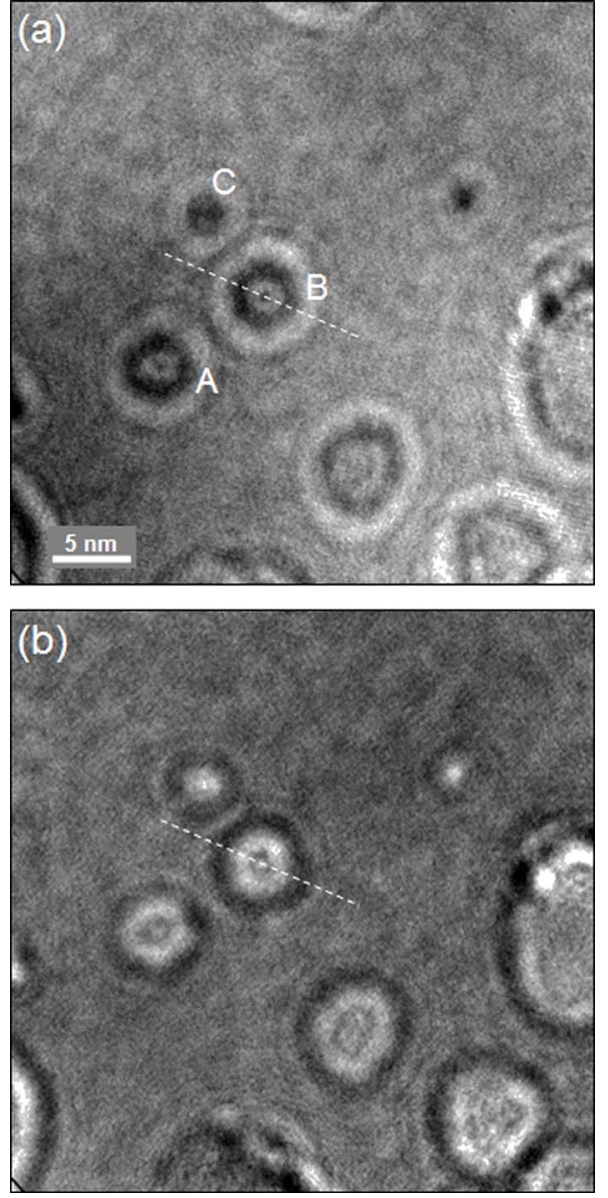

FIG. 3. Through focus TEM bright field micrographs of helium bubbles in an $\mathrm{Fe}-9 \% \mathrm{Cr}$ alloy after $8 \mathrm{keV} \mathrm{He}^{+}$implantation at $400{ }^{\circ} \mathrm{C}(11$ $\times 10^{4}$ at. ppm $\left.\mathrm{He}^{+}\right)$. (a) Underfocused $(\Delta f=-1 \mu \mathrm{m})$ image. (b) Overfocused $(\Delta f=+1)$ image.

\section{B. Characterization of helium bubble morphology using conventional TEM and EH}

As mentioned in Sec. II B, in TEM mode no evident contrast appears close to the exact focus conditions while Fresnel fringes appear on each side of the bubble/matrix interfaces as the objective lens is defocused. Figure 3(a) is a TEM image of He bubbles obtained for a negative defocus of $-1 \mu \mathrm{m}$ while in Fig. 3(b) is reported the same bubbles observed with a defocus of $+1 \mu \mathrm{m}$. As Fresnel fringes are located both inside and outside the "real" place of the bubbles, the measurement of their morphologies and sizes necessitates the simulation of these contrasts.

Phase images obtained from electron holograms are more directly interpretable. We reported in Figs. 4(a)-4(c) a hologram, the corresponding amplitude image, and phase image that have been obtained after processing using a reference hologram (not shown). Note that the hologram is taken in focus and therefore, as in conventional TEM imaging, no contrast appears in the amplitude image. ${ }^{20}$ As the phase shift is proportional to the MIP, the darkest areas in the phase image in Fig. 4(c) correspond to the location of bubbles where matter is missing. The gradual phase gradient is due to the variation in the sample thickness itself.

An enlargement of the phase image is reported in Fig. 5. Although some facets might be suggested from the low reso- 

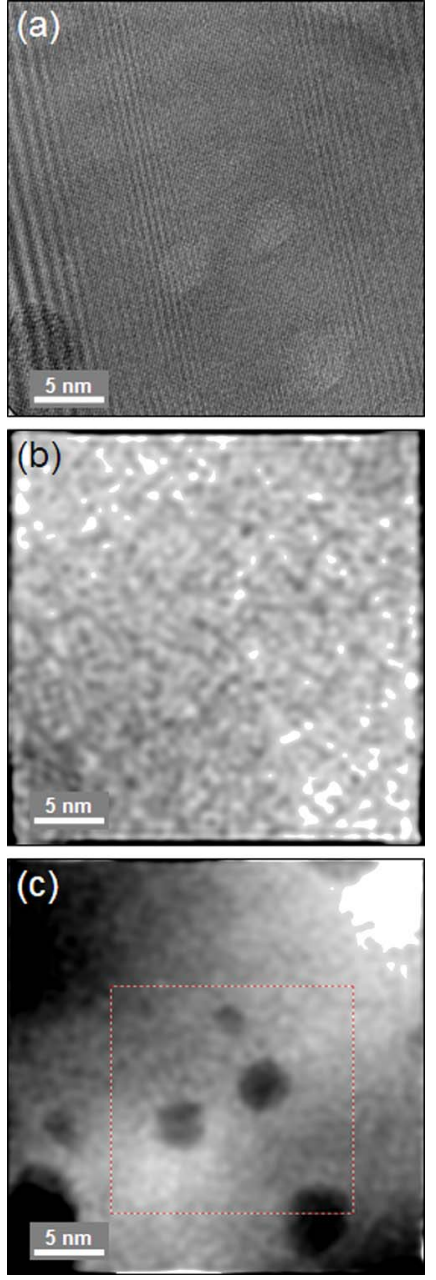

FIG. 4. (a) Hologram realized with a biprism voltage of 120 V. (b) Amplitude image. (c) Phase image.

lution Fresnel images in Fig. 3, the phase images clearly indicates a faceted shape of the particles, even for the smallest ones. These morphologies can be highlighted by adding contours on the phase images as reported in Fig. 5(b) or calculating the modulus of the phase gradient (Sobel filter) as reported on the image in Fig. 5(c). On the bubble located at the bottom left of the phase image in Fig. 5(a), the angles between the facets are measured in the range of $112^{\circ}-135^{\circ}$ leading to a distorted hexagonal shape of the bubble whose diameter is about $4 \mathrm{~nm}$.

Out off-focus Fresnel micrographs and phase images were compared making line profiles across one single bubble studied in the two different modes. The line along which the profiles were extracted are reported in Figs. 3(a)(underfocused), 3(b)(overfocused), and 5(a)(phase image). These profiles are plotted in Fig. 6. The oscillations of the contrast correspond to the Fresnel fringes appearing outside and inside the bubble on a out-of-focus TEM micrograph. The phase profile clearly shows the advantages of electron holography compared with Fresnel imaging. A direct and accurate measurement of shape can be achieved from the holographic phase profile, whereas extensive simulations of the fringe profiles would be necessary for Fresnel analysis. Using holography we measure a diameter of $4.2 \pm 0.2 \mathrm{~nm}$. The preci-
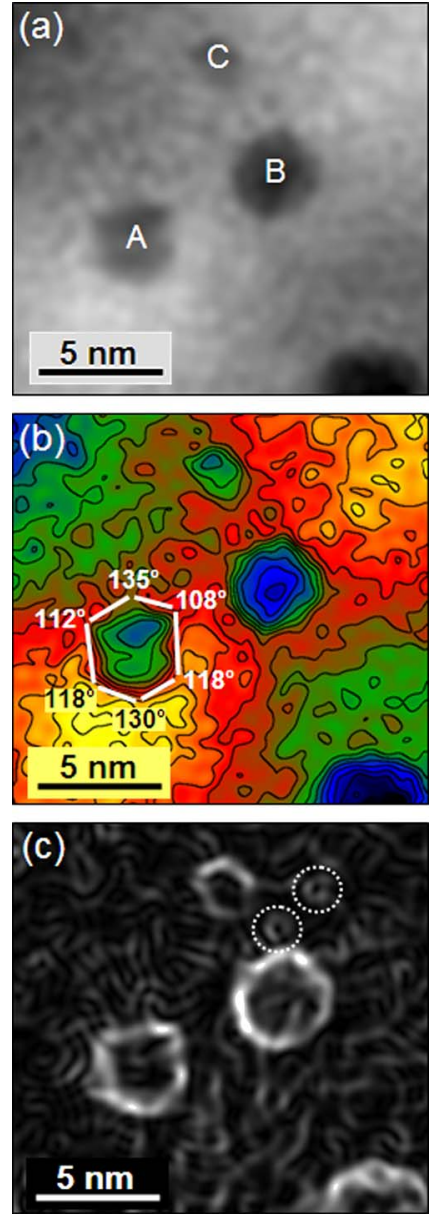

FIG. 5. (a) Enlargement of the area selected in the phase image of Fig 4(c) (b) $0.1 \mathrm{rad}$ contours superimposed to the phase image. (c) Sobel filtered image of the phase image.

sion comes both from the measurement and the fact that the bubble is not perfectly round. The maximum phase shift at the center of the bubble was $0.65 \pm 0.05$ rad. Similar measurements were carried out for the two other neighboring bubbles (Table II).

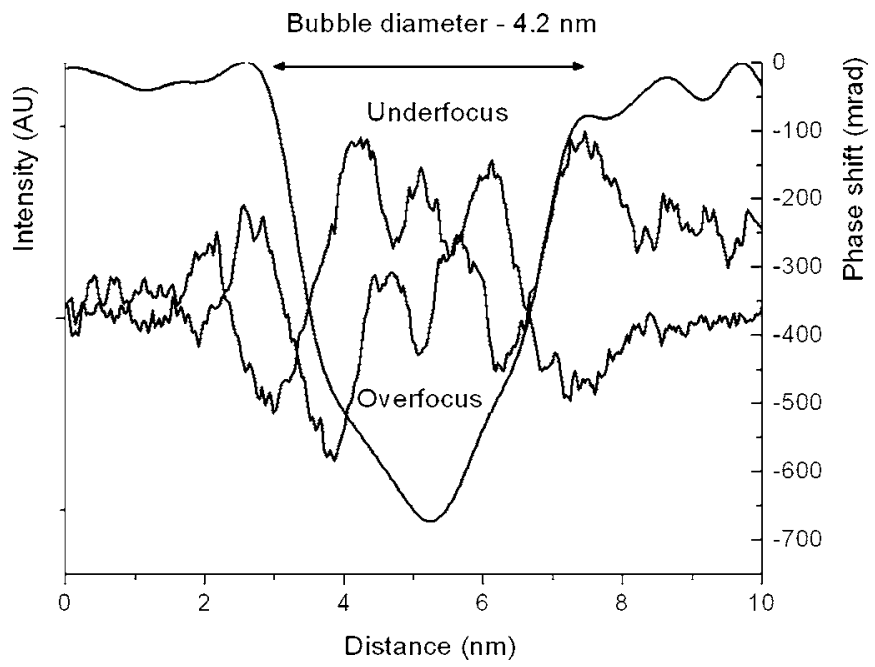

FIG. 6. Comparison of the profiles obtained on +1 and $-1 \mu \mathrm{m}$ out-of-focus TEM micrographs (dashed lines and left-handed scale), and the phase profile (solid line and right-handed scale) $t$ measured across a $4.2 \mathrm{~nm}$ diameter bubble. 
TABLE II. Analysis of bubble size and shape: lateral diameter measured from phase image, phase shift at center of bubble, and implied vertical diameter using Eq. (2)

\begin{tabular}{cccc}
\hline \hline Bubble & $\begin{array}{c}\text { Lateral diameter } \\
(\mathrm{nm})\end{array}$ & $\begin{array}{c}\text { Maximum phase shift } \\
(\mathrm{rad})\end{array}$ & $\begin{array}{c}\text { Vertical diameter } \\
(\mathrm{nm})\end{array}$ \\
\hline A & $4.2 \pm 0.2$ & $0.65 \pm 0.05$ & $4.2 \pm 0.3$ \\
B & $3.8 \pm 0.2$ & $0.40 \pm 0.05$ & $2.6 \pm 0.3$ \\
C & $2.2 \pm 0.2$ & $0.30 \pm 0.05$ & $2.0 \pm 0.3$ \\
\hline \hline
\end{tabular}

Using Eq. (2), the vertical dimension of the bubbles can be determined (see Table II). Bubbles A and C confirm the roughly spherical shape of the bubbles, as the lateral and vertical dimensions are the same. However, the apparent vertical size of bubble B is significantly smaller than its lateral dimensions. This suggests that the bubble is not completely embedded in the alloy but has been cut almost in half during the preparation of the thin foil. This would be near impossible to determine in the Fresnel imaging mode.

The precision of the measurement of lateral and vertical dimensions is nearly identical. This is not necessarily the case. Lateral resolution is determined by the signal-to-noise ratio in the phase. In this case, the lateral resolution of the phase images was $0.6 \mathrm{~nm}$ due to the mask used in the phase reconstruction. A larger mask could only be used with better signal-to-noise characteristics and finer holographic fringes. The measurement of the overall bubble size has a higher accuracy as this is an average measurement. The vertical size resolution is determined by the magnitude of the phase variations. These variations are due not only to noise but also the uneven nature of the specimen foil thickness. The standard deviation of the phase in a bubble-free region was measured as $0.05 \mathrm{rad}$, equivalent to $0.3 \mathrm{~nm}$ in thickness. Both spatial and vertical resolutions can be improved by better specimen preparation and a higher contrast for the holographic fringes (thus making finer fringe spacings possible). A factor of 2 improvement should be possible.

The minimum size of bubble detectable by electron holography is not the same as spatial resolution but is closely related. Sensitivity will be affected by both lateral and vertical resolutions: a smaller bubble will be simultaneously smaller in area and produce a smaller phase shift. One or two very small bubbles are visible in the phase images, particularly in the Sobel filtered image in Fig. 5(c). These appear to have a size of $1 \mathrm{~nm}$ but are difficult to quantify. Again, it is possible to improve the visibility of very small bubbles in future experiments.

\section{CONCLUSIONS}

A comparison between through focus TEM imaging and electron holography experiment was presented to study $\mathrm{He}$ bubbles in $\mathrm{Fe}-9 \% \mathrm{Cr}$ alloy obtained after $8 \mathrm{keV} \mathrm{He}{ }^{+}$ion implantation at $400{ }^{\circ} \mathrm{C}$. Our results reveal that electron holography is able to reveal the morphologies of He bubbles with diameters as small as $2.2 \mathrm{~nm}$. Fresnel analysis is based on out-of-focus TEM images which prevents the precise characterization of bubble morphologies: helium bubbles which look round shaped in Fresnel-type TEM are revealed to be faceted using EH.

Consequently, EH which is more accurate than conventional TEM and easier than high resolution TEM seems to be the better-adapted technique to detect the tiny helium bubbles that could take part in the alloy hardening process. Complementary studies are currently being led to determine the crystallographic planes and faceting directions of the helium bubbles. More generally, the technique of electron holography seems ideally suited to the study of the morphology of bubbles, cavities, and voids.

\section{ACKNOWLEDGMENTS}

The authors would like to thank O. Kaitasov for her helpful interactions on the helium implantation. One of the authors (J.M.) thanks the European MEGAPIE Program for its financial support.

${ }^{1}$ P. Jung, J. Henry, J. Chen, and J.-C. Brachet, J. Nucl. Mater. 318, 241 (2003).

${ }^{2}$ J. Majimel, B. Décamps, M. O. Ruault, E. Leroy, and D. Gorse, Acta Mater. (submitted).

${ }^{3}$ J. Henry, M. H. Mathon, and P. Jung, J. Nucl. Mater. 318, 249 (2003).

${ }^{4}$ J. L. Boutard and D. Gorse, CEA Report No. DECM 98.078, 1998 (unpublished).

${ }^{5}$ K. Arakawa, R. Imamure, K. Ohota, and K. Ono, J. Appl. Phys. 89, 4752 (2001).

${ }^{6}$ J. Chen, P. Jung, and H. Trinkaus, Phys. Rev. Lett. 82, 2709 (1996).

${ }^{7}$ J. Chen, P. Jung, and H. Trinkaus, Phys. Rev. B 61, 12923 (2000).

${ }^{8}$ C. A. Walsh, J. Yuan, and L. M. Brown, Philos. Mag. A 80, 1507 (2000).

${ }^{9}$ M. J. Loretto and R. E. Smallman, Defect Analysis in Electron Microcsopy (Wiley, New York, 1975).

${ }^{10}$ L. F. Allard, E. Wlkl, A. Carima, A. K. Datyeb, and R. RuoW, Nanostruct. Mater. 7, 137 (1996).

${ }^{11}$ C. Beeli, G. Matteucci, G. Lulli, P. G. Merli, and A. Migliori, Mater. Charact. 42, 241 (1999).

${ }^{12}$ F. Faudot, J. C. Rouchau, L. Debove, M. Fedoroff, and J. Bigot, J. Phys. Chem. Solids 48, 761 (1987).

${ }^{13}$ J. Bigot, Annales de Chimie (Paris) 5, 397 (1970).

${ }^{14}$ J. F. Ziegler, J. Biersack, and U. Littmark, The Stopping and Range of Ions in Solids (Pergamon, New York, 1966).

${ }^{15}$ D. Gabor, Rev. Mod. Phys. 28, 260 (1956).

${ }^{16}$ A. Tonomura, Electron Holography (Springer-Verlag, Berlin, 1993).

${ }^{17}$ L. Reimer, Transmission Electron Microscopy (Springer-Verlag, Berlin, 1997).

${ }^{18}$ R. E. Dunin-Borkowski, M. R. McCartney, and D. J. Smith, in Electron Holography of Nanostructured Materials, Vol. 3 of the Encyclopedia of Nanoscience and Nanotechnology, edited by H. S. Nalwa (American Scientific Publishers, 2004), pp. 41-100.

${ }^{19}$ M. Lehmann and H. Lichte, Electron Holography (Elsevier, Amsterdam, 1995), pp. 69-79.

${ }^{20}$ M. R. McCartney and M. Gajdardziska-Josifovska, Ultramicroscopy 53, 283 (1994). 